\title{
Factors that contribute significantly to Scrum adoption
}

\author{
Ridewaan Hanslo \\ Council for Scientific and \\ Industrial Research \\ Pretoria, South Africa \\ Email: rhanslo@csir.co.za
}

\author{
Ernest Mnkandla \\ University of South Africa, School \\ of Computing, College of Science, \\ Engineering and Technology \\ Pretoria, South Africa \\ Email: mnkane@unisa.ac.za
}

\author{
Anwar Vahed \\ Data Intensive Research Initiative \\ of South Africa \\ Pretoria, South Africa \\ Email: avahed@dirisa.ac.za
}

\begin{abstract}
Scrum is the most adopted Agile methodology. The research conducted on Scrum adoption is mainly qualitative and there is therefore a need for a quantitative study on Scrum adoption challenges. The primary objective of this paper is to present the findings of a study on the factors that have a significant relationship with Scrum adoption as perceived by Scrum practitioners working within South African organizations. Towards this objective, a narrative review to extract and synthesize the existing challenges was conducted. These synthesized challenges were used in the development of a conceptual framework for evaluating the challenges that have a correlation and linear relationship with Scrum adoption. Following this, a survey questionnaire was used to test and evaluate the factors forming part of the developed framework. The findings indicate that Relative Advantage, Complexity, and Sprint Management are factors that have a significant linear relationship with Scrum adoption. Our recommendation is that organizations consider these findings during their adoption phase of Scrum.

Index Terms - Adoption Challenges, Agile
\end{abstract} Methodologies, Diffusion of Innovation, Multiple Linear Regression, Narrative Review, Quantitative Research, Scrum.

\section{INTRODUCTION}

0 CRUM is regarded as one of the most under researched Agile methodologies [1], and the majority of research conducted in this field is qualitative in nature [2]. This paper focuses on bridging this literature gap between the body of qualitative knowledge on Scrum and the lack of sufficient quantitative literature on Scrum adoption within the South African (SA) context.

The author's previous paper on Scrum adoption challenges focused on developing a model that can be used to test and evaluate challenges to Scrum adoption [3]. To test and evaluate the Scrum adoption challenges a narrative review was conducted on the existing Agile and Scrum adoption challenges experienced globally and within SA. The synthesized challenges were used as the independent variables to the model. The first iteration of the Conceptual
Framework (CF) is known as the Scrum Adoption Challenges Detection Model (SACDM). The CF is a custom model adapted from the Diffusion of Innovation (DOI) theory and the study of the adoption of new technology by Sultan \& Chan [12]. The model is divided into four constructs, namely, Individual Factors $\left(X_{1}\right)$, Team Factors $\left(X_{2}\right)$, Organizational Factors $\left(X_{3}\right)$, and Technology Factors $\left(X_{4}\right)$. The independent variables are the factors within the constructs $X_{1}, X_{2}, X_{3}$ and $X_{4}$. The dependent variable is $Y$ with $Y=f\left(X_{1} \cdot X_{2} \cdot X_{3} \cdot X_{4}\right)$. When $Y=1$, the individual within an organization is an adopter of Scrum. When $Y=0$, the individual within the organization is a non-adopter of Scrum. The first iteration of the CF is similar to the second iteration except that the statistical analysis technique is modified from linear regression to logistic regression. For this reason, the first iteration is not depicted.

In the second iteration the statistical analysis technique used to evaluate the dependent variable changed from multiple logistic regression to multiple linear regression (MLR). The reason for this change was because of the need to test and evaluate whether there was a statistically significant linear relationship between the adoption challenges and Scrum adoption. Another reason was the small sample size which did not meet the requirement of a large sample size for logistic regression. Figure 1, displays the second iteration of the CF labelled as the Scrum Adoption Challenges Conceptual Framework (SACCF). Independent variables are depicted as factors within constructs $X_{1}, X_{2}, X_{3}$ and $X_{4}$. The dependent variable is $\mathrm{Y}$ with $Y=\beta_{0}+\beta_{1} X_{1}+\beta_{2} X_{2}+\beta_{3} X_{3}+\beta_{4} X_{4}+\epsilon$. The constants $\beta_{1}$ are the standardized coefficients (beta), and $\epsilon$ is the standard error. The hypothesized relationships between the independent variables and the dependent variable are shown by the symbols in parenthesis.

The third iteration is the final version of the CF. The statistical analysis technique for the second and third iteration is identical. The third iteration creates a new set of 14 validated factors from the second iteration's 19 factors. This iteration of the $\mathrm{CF}$ is discussed in Section V. A quantitative survey was conducted using an online survey questionnaire. A set of 207 valid responses to this survey 
was used to perform Exploratory Factor Analysis (EFA), and Cronbach's alpha analysis, which confirmed the validity and reliability of the survey instrument used.

The results from the correlational and MLR statistics were used to identify factors which have a significant linear relationship with Scrum adoption.

This paper consists of the following sections: Section II describes the background of the topic. Section III presents the methodology, including the statistical analysis techniques used to analyze and validate the data collection instrument. Section IV displays the results, followed by a discussion of the research findings in Section V. Section VI concludes the paper.

\section{BACKGROUND}

\section{a) Scrum Defined}

Scrum is one of many Agile software development methodologies available. Scrum has seen exponential growth in the past decade [7]. As a framework, Scrum allows organizations to improve on their project delivery objectives [17]. The Scrum guide written by Ken Schwaber and Jeff Sutherland describes this framework as lightweight, simple to understand, but extremely difficult to master [8].

Scrum embodies iterative and incremental development, and the framework is comprised of six artifacts, five roles, and four predominant activities [8].

\section{b) Agile Challenges}

The introduction of new methodologies typically poses challenges for individuals and organizations who make use of them [9]. The adoption of Agile methodologies creates additional challenges such as management style, software development process, and software developer resistance [2].

The Agile adoption challenges in the context of this paper is taken from the author's previous paper on the Scrum Adoption Challenges Detection Model (SACDM) [3]. The challenges were derived from Agile, Scrum, Software Development Methodology (SDM), and Information Systems (IS) literature. These challenges are encountered both within South Africa (SA) and globally (non-SA).

Due to Scrum research within SA being primarily qualitative in nature [10], other Agile methodology challenges were included in order to attain a more comprehensive model. Common challenges such as lack of experience, the Organizational Culture, and lack of communication have been identified during the narrative review.

\section{c) Theoretical Framework}

Research by Chan and Thong [11], and Mohan and Ahlemann [9] explains that previous IT adoption studies focused on the technical aspects of the innovation. These studies made use of technology adoption models, such as Technology Adoption Model (TAM). However, with complex Agile methodologies such as Scrum where collaboration between individuals within teams and organizations are important, a more inclusive model was required. The mixture of factors which affect adoption led to the selection the Diffusion of Innovation (DOI) theory as the theoretical lens for the Conceptual Framework (CF) [13].

The DOI theory is used in both organizational and individual adoption studies, with the DOI model composed of five characteristics of innovation. The five characteristics of innovation are Compatibility, Complexity, Observability, Relative Advantage, and Trialability [13].

In the authors' custom model, as shown in Figure 1, Compatibility, Complexity, and Relative Advantage are the three characteristics of innovation that have been retained. The reason for this decision was based on the consistency of the relationship between the three characteristics and adoption behavior as identified within innovation studies [14].

\section{METHODOLOGY}

\section{a) Research Design}

The research design consists of a narrative review and survey questionnaire. The narrative review is a literature review to assess a topics body of knowledge [15]. This review was conducted due to the lack of quantitative literature on Scrum adoption. The review extracted and synthesized the Scrum and Agile adoption challenges to form the factors of the Conceptual Framework $(\mathrm{CF})$.

The quantitative survey design operationalized the narrative reviews factors as the independent variables and Scrum adoption as the dependent variable. The online survey was used as the scale to measure the opinions of the Scrum practitioners working within SA organizations [16].

The validity of the scale was tested using a pilot study, Exploratory Factor Analysis (EFA), Bartlett's test for Sphericity, and Kaiser-Meyer-Olkin (KMO). Bartlett's test for Sphericity, EFA, and KMO are discussed in the analysis subsection. For reliability the Cronbach's coefficient alpha was used to measure internal consistency of the scale [16].

\section{b) Analysis}

EFA is a statistical method used to describe the variability of the observed variables in terms of the unobserved constructs [4]. The validation of the questionnaire items against the initial 19 factors in the SACCF required a first order and second order EFA to be conducted. In the first order EFA we considered the 78 survey questionnaire items to construct the newly validated 14 factors. These factors were subjected to a second order EFA in order to develop the four constructs. The validity analysis proceeded by generating the first order EFA scores. Once the first order EFA scores were summarized, the second order EFA followed. 


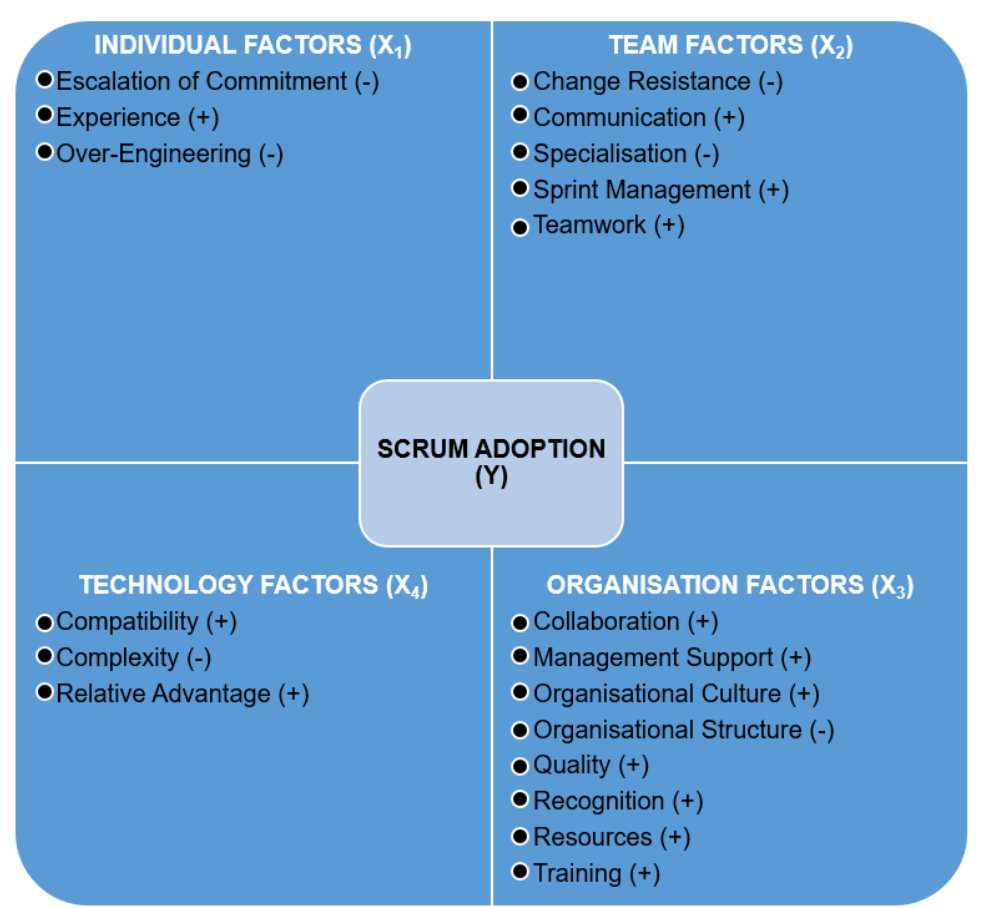

Figure 1: Scrum Adoption Challenges Conceptual Framework (SACCF).

To test the sampling adequacy, the KMO measure of sampling adequacy was used. The KMO value obtained was 0.88 . The Bartlett's test for Sphericity was conducted to determine if it was useful to conduct factor analysis. The Bartlett's test for Sphericity significance level was 0.00. These test results indicate that it was, therefore, worthwhile to conduct the EFA on the dataset.

To determine the number of factors derived from the individual statements, Eigenvalues $>1$ and the Scree plot were used. The constructs cumulative percentage was $75.8 \%$.

The Principal Axis Factoring (PAF) extraction method with oblique rotation was used to seek a parsimonious representation for the common variance (correlation) between variables by latent factors. The oblique rotation implemented the Oblimin with Kaiser Normalization method because it was required to explore the correlations between the factors.

To summarize, of the 78 questionnaire items, 14 factors were retained for rotation due to their Eigenvalues being greater than or near one. The first 14 factors as a collective accounted for $75.8 \%$ of the total variance.

Because of the factor loading cut-off criteria of $0.40,12$ items were found to load on the first factor, and these were subsequently labelled "Organizational Behavior". Eight items loaded on the second factor, labelled "Sprint Management". Nine items loaded on the third factor, labelled "Relative Advantage". Four items loaded on the fourth, fifth, sixth, and the seventh factor respectively, labelled "Experience", "Training", "Specialization", and
"Recognition". Seven items loaded on the eighth factor, labelled "Customer Collaboration". Three items loaded on the ninth factor, labelled "Compatibility". Five items loaded on the tenth factor, labelled "Over-Engineering". Three items loaded on the eleventh and twelfth factor respectively, labelled "Escalation of Commitment", and "Complexity". Eight items loaded on the thirteenth factor, labelled "Teamwork", and four items loaded on the fourteenth factor labelled "Resource Management". Table 1 displays the mapping of the initial $19 \mathrm{CF}$ factors to the validated 14 factors.

The second order EFA was conducted on the 14 factors derived from the first order EFA output. The PAF extraction method and the Oblimin with Kaiser Normalization (oblique) rotation method were used to calculate the scores. The second order EFA generated the KMO measure of sampling adequacy test result of 0.779 and a Bartlett's test for Sphericity significance level of 0.00 which made it viable to conduct an EFA. The Eigenvalues generated from the PAF extraction method resulted in 4 constructs, with the Eigenvalues greater than or near 1 and the Scree plot identifying the valid constructs. The cumulative percentage explained by the four constructs is $67.8 \%$.

In summary the second order EFA was applied to the 14 factors calculated in the first order EFA. The PAF method was used to extract the factors, followed by the Oblimin with Kaiser Normalization (oblique) rotation method. Of the 14 input factors, only four factors were retained for rotation, because of their Eigenvalue being 
greater than or near one. The first four factors as a collective accounted for $67.8 \%$ of the cumulative variance. These four factors are consequently referred to as the four constructs of the SACCF.

Table 1: Mapping of the initial 19 factors to the validated 14 factors.

\begin{tabular}{|c|c|}
\hline $\begin{array}{l}\text { Fourteen Factors Loaded } \\
\text { from Questionnaire Items }\end{array}$ & $\begin{array}{c}\text { Nineteen Factors } \\
\text { based on Literature Review }\end{array}$ \\
\hline Organizational Behavior & $\begin{array}{l}>\text { Organizational Structure } \\
>\text { Management Support } \\
>\text { Organizational Culture }\end{array}$ \\
\hline Sprint Management & $\begin{array}{l}>\text { Sprint Management } \\
>\text { Change Resistance }\end{array}$ \\
\hline Relative Advantage & $>$ Relative Advantage \\
\hline Experience & $>$ Experience \\
\hline Training & $>$ Training \\
\hline Specialization & $>$ Specialization \\
\hline Recognition & $>$ Recognition \\
\hline Customer Collaboration & $\begin{array}{l}>\text { Collaboration } \\
>\text { Quality }\end{array}$ \\
\hline Compatibility & $>$ Compatibility \\
\hline Over-Engineering & $>$ Over-Engineering \\
\hline Escalation of Commitment & $>$ Escalation of Commitment \\
\hline Complexity & $>$ Complexity \\
\hline Teamwork & $\begin{array}{l}>\text { Teamwork } \\
>\text { Communication }\end{array}$ \\
\hline Resource Management & $>$ Resources \\
\hline
\end{tabular}

\section{RESULTS}

The previous section described the methodology used to derive to the validated factors and constructs of the Conceptual Framework (CF). A statistical analysis of the results derived with this methodology, is presented in this section.

\section{a) Testing the Fourteen First Order Factor Relationship Strength}

A correlation matrix was used to test for the relationship strength among the different factors. A Spearman correlation analysis was conducted on all the factors as opposed to a Pearson correlation analysis, due to the skewness of the data discovered during the normality tests. The Spearman correlation analysis revealed statistically significant correlations for the relationships between Scrum Adoption and all the factors at the 0.01 level, except for Teamwork which was significant at the 0.05 level $(p=0.018)$, and OverEngineering with no significance $(\mathrm{p}=0.514)$, see Table 2 .

\section{b) Testing the Four Second Order Factor Relationship Strength}

A correlation matrix was used to test the relationship strength among the four constructs, as well as between the four constructs and the dependent variable. A Spearman correlation analysis was conducted as opposed to a Pearson correlation analysis, due to the skewness of the data discovered during the normality tests. Spearman correlation analysis revealed statistically significant correlations for the relationships between Scrum Adoption and the four constructs at the 0.01 level, see Table 3 .

\section{c) Testing the Statistical Significance of the Factor Relationship}

All the normality assumptions were met when a regression analysis was conducted on the 14 factors. Tolerance values were above .01, and all the VIF values were below 10, and the assumption of no multicollinearity was met. The Durbin-Watson statistic fell within an expected range, which suggests that the assumption of no autocorrelation of residuals was met. The assumptions of linearity and homoscedasticity were also met, since the Scatterplot of standardized residual and standardized predicted value did not curve or funnel out. The normal probability plot of the residuals was approximately linear, which suggests that the assumption of normality of residuals was also met.

For the 14 factors, Multiple Linear Regression (MLR) was conducted to examine whether Over-Engineering, Relative Advantage, Recognition, Experience, Teamwork, Specialization, Escalation of Commitment, Compatibility, Resource Management, Customer Collaboration, Complexity, Training, Sprint Management, and Organizational Behavior impact on Scrum Adoption. The overall model (predictors: Over-Engineering, Relative Advantage, Recognition, Experience, Teamwork, Specialization, Escalation of Commitment, Compatibility, Resource Management, Customer Collaboration, Complexity, Training, Sprint Management, Organizational Behavior) explained $52.9 \%$ of the variance of Scrum Adoption, which was revealed to be statistically significant $(F(14,206)=15.40, \mathrm{p}<0.0001)$. 


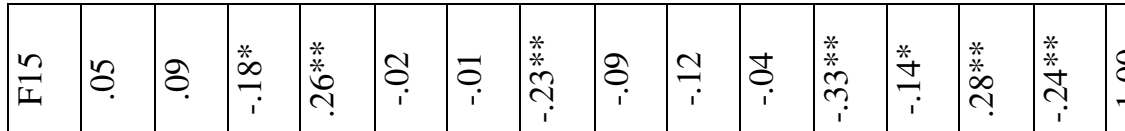

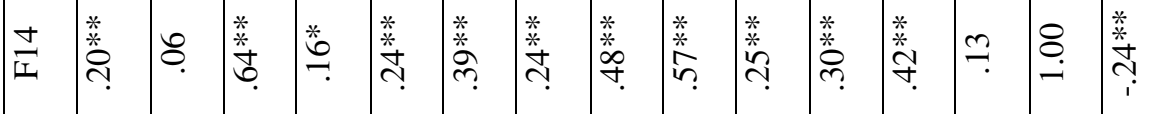

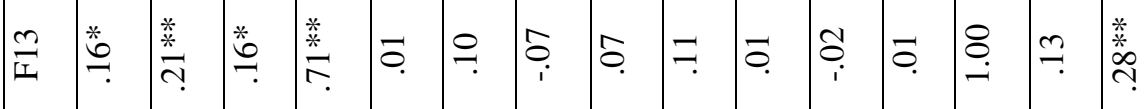

至

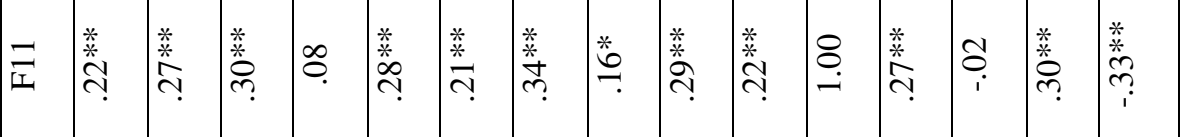

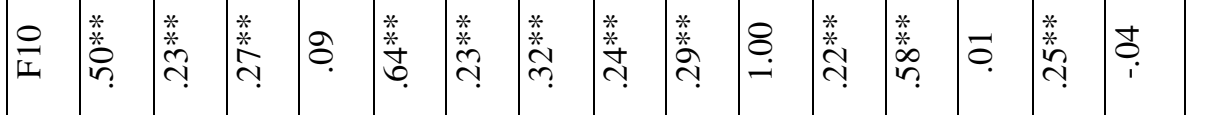

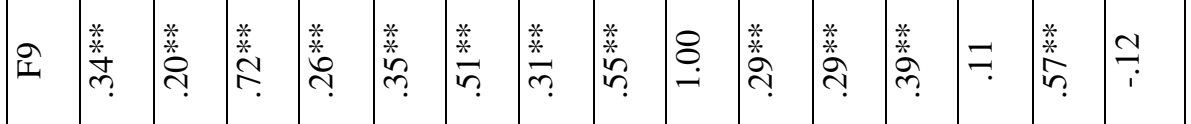

事 丵

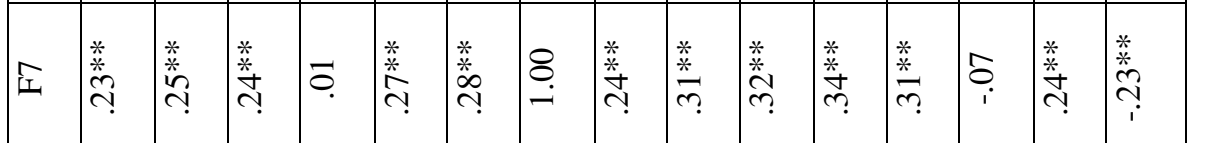

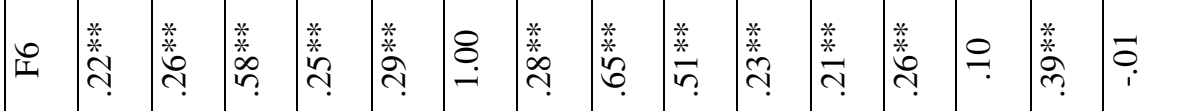

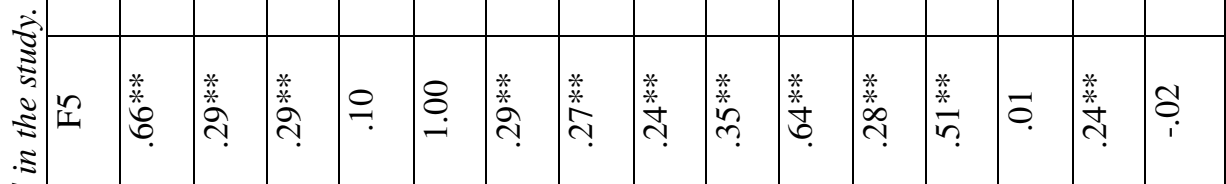

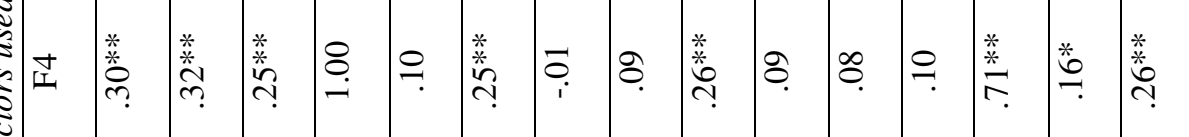

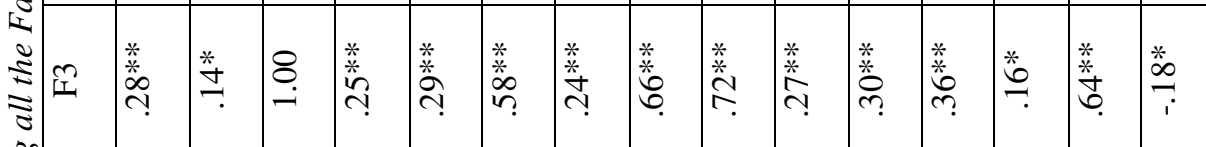

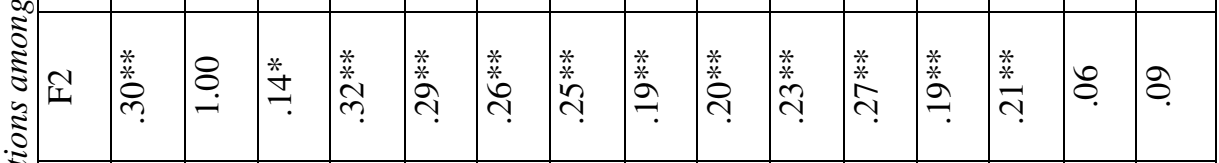

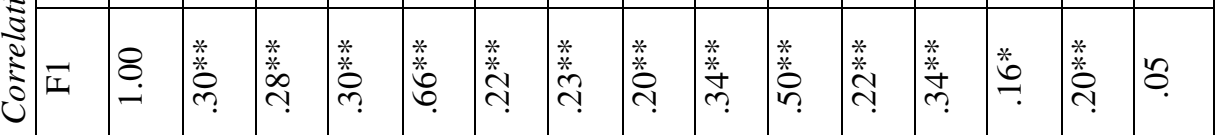

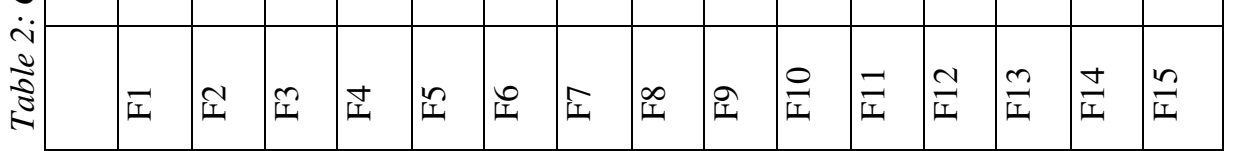

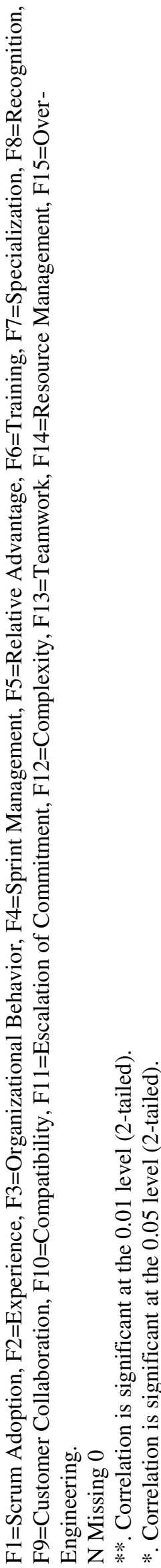


Table 3: Correlations between the Four Constructs and Scrum Adoption.

\begin{tabular}{|l|c|c|c|c|c|}
\hline & Scrum Adoption & Individual & Organization & Team & Technology \\
\hline Scrum Adoption & 1.00 & $.29^{* *}$ & $.30^{* *}$ & $.20^{* *}$ & $.53^{* *}$ \\
\hline Individual $^{1}$ & $.29^{* *}$ & 1.00 & $.39^{* *}$ & $.16^{*}$ & $.38^{* *}$ \\
\hline Organization $^{*}$ & $.30^{* *}$ & $.39^{* *}$ & 1.00 & $.25^{* *}$ & $.42^{* *}$ \\
\hline Team & $.20^{* *}$ & $.16^{*}$ & $.25^{* *}$ & 1.00 & .07 \\
\hline Technology & $.53^{* *}$ & $.38^{* *}$ & $.42^{* *}$ & .07 & 1.00 \\
\hline
\end{tabular}

N Missing 0

**. Correlation is significant at the 0.01 level (2-tailed).

*. Correlation is significant at the 0.05 level (2-tailed).

$1=$ factor's negatively phrased questions were recoded.

An inspection of the individual predictors of the overall model revealed that Relative Advantage (Beta $=0.688$, $\mathrm{p}<0.0001$ ), Sprint Management (Beta=0.109, $\mathrm{p}<0.05)$, and Complexity (Beta=0.041, $\mathrm{p}<0.05)$ are significant predictors of Scrum Adoption (Table 4). Higher levels of Relative Advantage are associated with higher levels of Scrum Adoption, higher levels of Sprint Management are associated with higher levels of Scrum Adoption, and higher levels of Complexity are associated with lower levels of Scrum Adoption.

For the four constructs, MLR was conducted to examine whether Individual Factors, Technology Factors, Team Factors, and Organization Factors impact on Scrum Adoption. The overall model explained $33.40 \%$ of the variance in Scrum Adoption, which was revealed to be statistically significant $(\mathrm{F}(4,206)=25.34, \mathrm{p}<0.0001)$. An inspection of the individual predictors revealed that Technology Factors $(B e t a=0.580, \mathrm{p}<0.0001)$ and Team Factors $($ Beta $=0.126, \mathrm{p}<0.05)$ are significant predictors of Scrum Adoption (see Table 5). Higher levels of Technology Factors are associated with higher levels of Scrum Adoption, and higher levels of Team Factors are associated with higher levels of Scrum Adoption.

\section{DISCUSSION OF FINDINGS}

It is important to note that initially, the Scrum Adoption Challenges Conceptual Framework (SACCF) had 19 factors (independent variables). However, during the validation of the scale, the Exploratory Factor Analysis (EFA) applied to the questionnaire items extracted 14 factors. The loading of the questionnaire items to new factors meant that the initial predicted model had to be evaluated. The questionnaire items with its commonalities and corresponding factor loadings were studied and it was found that the initial 19 independent variables loaded correctly into the 14 factors. The new factor loadings, therefore, made logical sense. In Table 1, as discussed in
Section III, the 19 hypothesized factors are mapped to the newly validated 14 factors.

While most of the mappings in Table 1 is selfexplanatory, it is necessary to give an explanation of the four factors that have more than one variable. These four factors are:

- Organizational Behavior

- Sprint Management

- Customer Collaboration

- Teamwork

The term Organization Behavior (OB) is defined as the actions and attitudes of individuals that work within an organization. $\mathrm{OB}$ is, therefore, the study of human behavior within the organizational environment, how human behavior interacts with the organization, and the organization itself [5]. George et al. [5], also states that the manner in which managers manage others is significantly affected by OB. Given this perspective of $\mathrm{OB}$, it is reasonable to load Organizational Structure, Management Support, and Organizational Culture as a single factor under the heading OB.

The loading of Sprint Management and Change Resistance into a single factor is also logically sensible since firstly, Sprint Management is a time-boxed activity. Scrum practitioners would be performing their tasks within a Scrum sprint under most circumstances although it is recognized that this may not be the case for every task performed. Consequently, if a team is resisting change, it would manifest when the change is requested or performed during the Scrum sprint. To reiterate the fourth value of Agile development, which is "responding to change over following a plan", it is therefore fitting that Sprint Management and Change Resistance loaded as the Sprint Management factor, since Change Resistance by default, is part of the Sprint Management cycle [6]. 
Table 4: Regression Coefficients of the 14 Factors.

\begin{tabular}{|c|c|c|c|c|c|c|}
\hline & & & Coefficients & & & \\
\hline & & $\begin{array}{r}\text { Uns } \\
\mathrm{Co}\end{array}$ & $\begin{array}{l}\text { ndardized } \\
\text { fficients }\end{array}$ & Standardized Coefficients & & \\
\hline & & B & Std. Error & Beta & $\mathrm{t}$ & Sig. \\
\hline 1 & (Constant) & .506 & .454 & & 1.114 & .267 \\
\hline & Experience & -.021 & .051 & -.026 & -.419 & .676 \\
\hline & Organizational Behavior & .000 & .062 & .000 & .003 & .998 \\
\hline & Sprint Management $^{1}$ & .109 & .049 & .178 & 2.239 & .026 \\
\hline & Relative Advantage & .688 & .068 & .702 & 10.168 & .000 \\
\hline & Training & -.031 & .052 & -.045 & -.604 & .547 \\
\hline & Specialization & .004 & .042 & .006 & .103 & .918 \\
\hline & Recognition & -.019 & .047 & -.032 & -.410 & .682 \\
\hline & Customer Collaboration & .118 & .062 & .151 & 1.900 & .059 \\
\hline & Compatibility & .085 & .058 & .099 & 1.477 & .141 \\
\hline & Escalation of Commitment & .011 & .041 & .018 & .280 & .780 \\
\hline & Complexity & -.116 & .056 & -.146 & -2.061 & .041 \\
\hline & Teamwork $^{1}$ & -.013 & .047 & -.021 & -.279 & .781 \\
\hline & Resource Management & -.042 & .051 & -.059 & -.830 & .407 \\
\hline & Over-Engineering $^{1}$ & .004 & .039 & .005 & .092 & .927 \\
\hline
\end{tabular}

a. Dependent Variable: Scrum Adoption

$1=$ factor's negatively phrased questions were recoded.

Table 5: Regression Coefficients of the 4 Constructs.

\begin{tabular}{|c|c|c|c|c|c|c|}
\hline \multicolumn{7}{|c|}{ Coefficients $^{\mathbf{a}}$} \\
\hline & & \multicolumn{2}{|c|}{ Unstandardized Coefficients } & \multirow{2}{*}{$\begin{array}{c}\text { Standardized Coefficients } \\
\text { Beta }\end{array}$} & \multirow[b]{2}{*}{$\mathrm{t}$} & \multirow[b]{2}{*}{ Sig. } \\
\hline \multicolumn{2}{|c|}{ Model } & B & Std. Error & & & \\
\hline \multirow[t]{5}{*}{1} & (Constant) & 1.197 & .445 & & 2.692 & .008 \\
\hline & Team $^{1}$ & .126 & .062 & .123 & 2.040 & .043 \\
\hline & Technology & .580 & .064 & .566 & 9.009 & .000 \\
\hline & Individual $^{1}$ & .016 & .053 & .019 & .303 & .763 \\
\hline & Organization & -.033 & .054 & -.039 & -.616 & .539 \\
\hline
\end{tabular}

a. Dependent Variable: Scrum Adoption

1=factor's negatively phrased questions were recoded. 
The loading of Collaboration and Quality into the Customer Collaboration factor was easy to accept since Customer Collaboration entails working closely with the client in order to deliver what was requested at the expected quality. The last merged factor loading was Teamwork which consists of Teamwork and Communication. This factor loading was also a simple decision and with hindsight, these two factors had to be grouped together from the outset. The reason for this is because Teamwork requires individuals to work together to complete tasks, and communication is a critical component to complete sprint tasks within the team. It is important to note that the Resources factor has been renamed to Resource Management because resource shortage or surplus is a management related concern.

Figure 2 displays the third and final iteration of the CF. The hypothesized relationships between the independent variables and the dependent variable are shown in the parenthesis. As is evident from the diagram, the conceptual model is much more refined than the previous iterations. The Specialization factor which was previously under the team construct is now under the individual construct, and Over-Engineering which was an individual factor is now a team factor. The reason for these realignments is because Specialization or specialized skills can be narrowed down to the individual level. OverEngineering, if encountered and allowed within a Scrum team environment, means that the team was not vigilant enough during their communication sessions to identify when an individual was doing more than what was required.

Four of the initial 19 factors were revealed as having a significant linear relationship with Scrum adoption. The four factors are Relative Advantage, Complexity, Change Resistance, and Sprint Management. The factor that came close to having a significant relationship with Scrum adoption was Customer Collaboration with $\mathrm{p}=0.059$. Because of the new factor loadings Sprint Management and Change Resistance loaded onto Sprint Management, as noted earlier.

\section{CONCLUSION}

Scrum and Agile software development, including Scrum adoption, is a growing phenomenon. The research presented in this paper contributes both towards the Agile body of knowledge and to Scrum adoption. A proposed consolidation of Scrum and Agile challenges, a Conceptual Framework (CF), and the evaluation of the $\mathrm{CF}$ using quantitative methods and techniques were explored in this paper. The primary objective of this paper was the investigation of factors that have a significant linear relationship with Scrum adoption as perceived by Scrum practitioners working within SA organizations. Three validated factors which have a significant linear relationship with Scrum adoption have been identified.

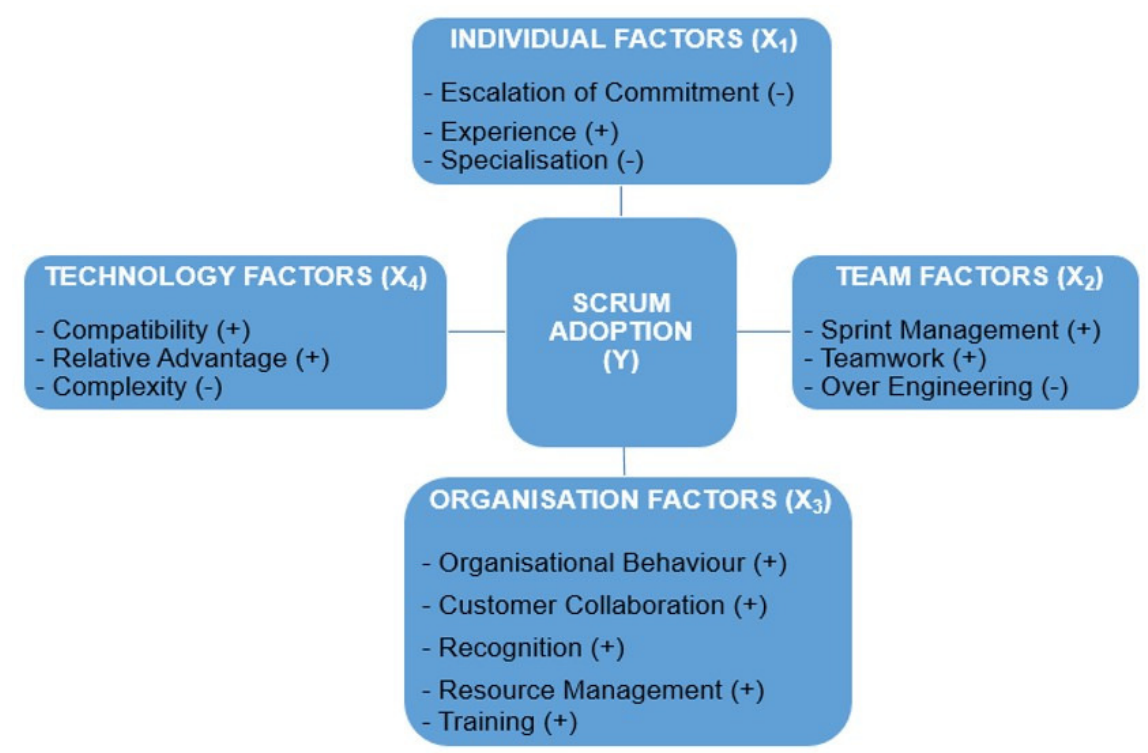

Figure 2: Final Iteration of the Conceptual Framework. 
This research can be extended by a systematic review of existing Scrum and Agile adoption challenges, as well as a larger population sample for greater generalization of the findings. For future research it would be beneficial to develop a logistic regression model for predicting an organizations success rate at Scrum adoption based on the organization's current practices. The predictive analysis can be conducted by comparing the test data of the organization to the trained data model derived from the population sample.

\section{REFERENCES}

[1] Overhage, S., Schlauderer, S., Birkmeier, D. \& Miller, J. 2011. What Makes IT Personnel Adopt Scrum? A Framework of Drivers and Inhibitors to Developer Acceptance. In 2011 44th Hawaii International Conference on System Sciences. IEEE: 1-10. http://ieeexplore.ieee.org/lpdocs/epic03/wrapper.htm? arnumber $=5718964$

[2] Chan, K.Y. \& Thong, J.Y.L. 2007. An Integrated Framework of Individual Acceptance of Agile Methodologies. PACIS 2007 Proceedings: 154 .

[3] Hanslo, R. \& Mnkandla, E. 2018. Scrum Adoption Challenges Detection Model: SACDM. In Federated Conference on Computer Science and Information Systems (FedCSIS). Poznan, Poland: IEEE: 949-957.

[4] Gerber, H. \& Hall, R. 2016. Statistical analysis reporting template for researchers.

[5] George, J.M., Jones, G.R. \& Sharbrough, W.C. 2005. Understanding and managing organizational behavior. Upper Saddle River, NJ: Pearson Prentice Hall.

[6] Beck, K., Beedle, M., Van Bennekum, A., Cockburn, A., Cunningham, W., Fowler, M., Grenning, J., Highsmith, J., Hunt, A.,
Jeffries, R., Kern, J., Marick, B., Martin, R.C., Mellor, S., Schwaber, K., Sutherland, J. \& Thomas, D. 2001. Agile Manifesto. Software Development, 9. http://agilemanifesto.org/.

[7] VersionOne. 2015. 9th Annual State of Agile Survey. http://stateofagile.versionone.com/.

[8] Schwaber, K. \& Sutherland, J. 2011. The scrum guide. Scrum.org, October, 2: 17. https://www.scrum.org/index.php/resources/scrumguide.

[9] Mohan, K. \& Ahlemann, F. 2013. Understanding acceptance of information system development and management methodologies by actual users: A review and assessment of existing literature. International Journal of Information Management, 33(5): 831-839.

[10] Noruwana, N. \& Tanner, M. 2012. Understanding the structured processes followed by organisations prior to engaging in agile processes: A South African Perspective. SACJ, (48): 8.

[11] Chan, F.K.Y. \& Thong, J.Y.L. 2009. Acceptance of agile methodologies: A critical review and conceptual framework. Decision support systems, 46(4): 803-814.

[12] Sultan, F. \& Chan, L. 2000. The adoption of new technology: the case of object-oriented computing in software companies. IEEE transactions on Engineering Management, 47(1):106-126.

[13] Rogers, E.M. 2003. Diffusion of Innovations, 5th Edition. Free Press. https://books.google.co.za/books?id=9U1K5LjUOwEC.

[14] Kishore, R. \& McLean, E.R. 2007. Reconceptualizing innovation compatibility as organizational alignment in secondary IT adoption contexts: an investigation of software reuse infusion. IEEE Transactions on Engineering Management, 54(4): 756-775.

[15] Derish, P.A. and Annesley, T.M., 2011. How to write a rave review. Clinical Chemistry, 57(3), pp.388-391.

[16] Welman, C., Kruger, F. \& Mitchell, B. 2005. Research Methodology. 3rd ed. Cape Town, South Africa: Oxford University Press.

[17] Dingsøyr, T., Hanssen, G.K., Dybå, T., Anker, G. \& Nygaard, J.O. 2006. Developing Software with Scrum in a Small CrossOrganizational Project. In I. Richardson, P. Runeson, \& R. Messnarz, eds. Software Process Improvement. Joensuu: Springer: 5-15. http://link.springer.com/10.1007/11908562_2. 